\title{
LA REFORMA DEL ESTADO: DEMOCRACIA Y GOBERNABILIDAD
}

\author{
Rafael de la Cruz (*)
}

\section{UNA ERA DE CAMBIOS.}

América Latina está experimentando una de las transformaciones más importantes de su historia. Tal vez, desde la consolidación de los Estado-nación entre fines del siglo pasado y las primeras décadas del actual, no se había presentado un reto tan exigente a la región.

El programa de ajuste estructural de la economía, para corregir las distorsiones acumuladas por viejas políticas proteccionistas, el desarrollo de reformas políticas y de descentralización en casi todos los países y el proceso de integración son los tres ejes más notorios de los cambios en curso. En conjunto, son la base de lo que podemos llamar la reforma integral del Estado.

Los últimos años han sido testigos de este inmenso movimiento que ha desbancado las tradicionales teorías asociadas a la sustitución de importaciones, y ha dado duros golpes al populismo característico de los sistemas políticos latinoamericanos. Igualmente, ha sido este mismo impulso renovador el que ha traído consigo una disminución grave del nivel de vida de los pueblos, amenazas a la estabilidad de los regímenes democráticos y un descenso apreciable del margen de gobernabilidad de estos países.

Desde un extremo al otro del continente encontramos síntomas de deslegitimación de los gobiernos e, incluso, de los regímenes políticos. México, a pesar de haber dado pasos de gran importancia en dirección de su democratización, debe probar aún su capacidad de alternabilidad gubernamental. Centroamérica, aunque pasa por uno de sus momentos menos beligerantes, encara graves problemas económicos, políticos y-sociales, que obligan a la prudencia aún en los pronósticos más optimistas sobre su recuperación y estabilización. Algunas islas del Caribe se encuentran en una situación de depresión económico-social tan aguda que encabezan la lista de los países más pobres del mundo.

Colombia no logra reunir la voluntad de la mayoría de la población alrededor del régimen democrático. Sus instituciones son débiles y en algunos casos inexistentes. La abstención electoral que no cesa, parece mostrar que el importante esfuerzo que se realizó a través de la nueva Constitución para aumentar la participación de la sociedad, no ha dado los resultados que se esperaban, y continúan existiendo varios Estados, varias Colombias superpuestas. Perú es una sociedad casi ingobernable, en la que las instituciones públicas están permanentemente al borde de la desaparición. La escasa integración de su inmensa población indígena a la economía formal y a la sociedad civil moderna (factor que comparte con Ecuador y Bolivia), es una fuente potencial de perturbaciones políticas de consecuencias imprevisibles.

Las jóvenes democracias del Cono Sur han navegado con dificultades entre asonadas militares como las que ha tenido que sortear Argentina, y negociaciones delicadas y siempre frágiles entre el poder civil y el militar como en el caso de Chile. Brasil registra uno de los más complejos momentos de su historia, carente de organizaciones de mediación política estables, con una pobreza en crecimiento constante y una desaceleración profunda de los efectos de su otrora milagro económico. Las matanzas de niños en las calles de sus principales ciudades son sólo un ejemplo de las dificultades que experimenta este país para mantener la autoridad y credibilidad de las instituciones públicas. Paraguay, a tientas en su proceso de democratización, ve pender siempre la amenaza de una vuelta al pasado dictatorial y autárquico en medio de un ambiente latinoamericano titubeante.

Finalmente, una de las democracias más antigua y aparentemente más fuerte de América Latina, ha visto cómo se estremece su viabilidad con un intento fracasado de golpe de estado en febrero de 1992. En Venezuela, precisamente uno de los países donde se está aplicando con más decisión y empuje la reforma del Estado, el apoyo que manifestó una parte de la sociedad a una intervención militar, deja muchas interrogantes abiertas que deben ser respondidas por quiénes apuestan al cambio en democracia.

Nos encontramos así ante una paradoja de cuya resolución puede depender el destino del continente.

Son pocos los que objetan a estas alturas la necesidad de las reformas económicas. Sin embargo, el tiempo de maduración que requieren para dar resultados que sean apreciados por la población, parece ser demasiado para las necesidades cada vez más apremiantes de los más pobres y de las clases medias depauperadas. Dos casos exitosos, el

(*) Politólogo y doctor en economía de la Universidad de París. Profesor Universitario. Coordinador del Programa de las Naciones Unidas que asiste a la Comisión Presidencial para la Reforma del Estado del Gobierno de Venezuela 
de Chile y el de Bolivia, son a su vez cuestionados desde ángulos diversos. Respecto al primero, se discute que la bonanza que se advierte en el país está sustentada en años de privaciones graves bajo el régimen dictatorial, y en una cesta limitada de productos de exportación que hace frágil estructuralmente su economía. En cuanto a Bolivia, a pesar de unas condiciones más que favorables logradas para la inversión extranjera y la estabilización de las variables macroeconómicas fundamentales, la llegada de capitales se hace esperar. El tesoro de la Nación es tan angosto, que altos funcionarios del gobierno deben ser pagados con fondos de organismos internacionales.

Estas situaciones, mantienen un estado de incertidumbre sobre el futuro económico de la región, que abona el terreno de la ingobernabilidad.

A su vez, los cambios políticos, desde la emergencia de regímenes democráticos en los últimos años (Brasil, Argentina, Chile, Paraguay, Uruguay, Nicaragua, E1 Salvador, entre otros) hasta los procesos inéditos de democratización de la democracia (Venezuela, Colombia y México), necesitan también un tiempo para mostrar sus bondades a una población escéptica. Adicionalmente, las reformas del Estado en el campo de lo político, especialmente la descentralización, se encuentran ante la oposición de las viejas capas de políticos populistas que ven amenazadas sus posiciones por la emergencia de nuevos liderazgos y nuevas reglas de juego entre el Estado y la sociedad. El enfrentamiento que se escenifica en casi toda América Latina entre ambas corrientes no ayuda a estabilizar las instituciones y los acuerdos de gobierno.

En el trabajo que presentamos, se discute esta disyuntiva desde la experiencia venezolana. Se realiza un análisis de las reformas adelantadas en Venezuela, y conclusiones útiles para el futuro. Se incluye una rápida revisión de las políticas económicas adelantadas en el país, sin lo cual el entorno que analizamos quedaría incompleto.

\section{EL LARGO CAMINO HACIA UNA ECONOMIA MODERNA.}

Cuando en Enero de 1989 asumió la presidencia de Venezuela Carlos Andrés Pérez, encontró que las reservas internacionales habían descendido hasta el asombroso nivel de 2.000 millones de US\$ (equivalente a poco menos de tres meses de importaciones), en un país de apenas 20 millones de habitantes, cuyas exportaciones petroleras llegaron a 9.800 millones de US\$, que sumados al resto de las exportaciones alcanzaron la cifra de 13.000 millones de US\$ para ese año (1).

La única explicación para este increíble hecho es que su predecesor y compañero de partido, Jaime Lusinchi, decidió financiar el prestigio de sus últimos tiempos en el gobierno, en buena medida con el agotamiento de las reservas de la
Nación, subsidiando un nivel de gasto público completamente disociado de los ingresos reales. De este modo, esquivó su responsabilidad de enfrentar la grave crisis económica que amenazaba a Venezuela. Este es uno de los mejores ejemplos del populismo que ha sobrevivido como práctica en el continente, y que llevó al país a una virtual bancarrota.

La nueva administración actuó desde el primer momento con un paquete de medidas que modificaron radicalmente el papel del Estado en la producción, control y planificación de la actividad económica.

\section{EL DIAGNOSTICO QUE SE REALIZO.}

Las circunstancias en las que se desenvolvió la economía venezolana en las últimas décadas de proteccionismo arancelario, subsidios monetarios, al consumo y a la producción, control de precios y creciente intervención del Estado en la producción directa, originaron una serie de deficiencias y desequilibrios estructurales.

El primer signo visible de esta crisis se presentó en 1983. De una paridad de 4.3 Bolívares por US\$ para esa fecha, se pasó a $65 \mathrm{Bs}$. por US\$ en nueve años. Este acontecimiento que parece poco significativo para la mayoría de las economías latinoamericanas, para Venezuela es un trauma mayor, considerando la estabilidad secular de la moneda. A pesar de las señales cada vez más insistentes que daba la economía (entre los cuales la inflación promedio de $20 \%$ en la década de los ochenta en un país que no pasaba de un dígito hasta mediados de los setenta) no se analizaron hasta 1989 con la necesaria profundidad los elementos a corregir. A continuación los más importantes:

\section{a. Ineficiencia del aparato productivo.}

Las grandes inversiones públicas y la demanda agregada creciente del Estado en la década de los 70 ayudaron a extender el aparato productivo público y privado. Sin embargo, no se produjeron en la cantidad necesarias corrientes de exportación importantes, ni se estabilizaron los precios, ni aumentó la calidad de la mayoría de los productos. Probablemente la razón más importante de ésto fue la poca competitividad que mostraban los productores venezolanos, acostumbrados a que el Estado los socorría ante cualquier percance.

\section{b. Dependencia extrema del ingreso petrolero.}

El ritmo poco acelerado de crecimiento de las exportaciones no petroleras ha incrementado la dependencia de Venezuela respecto al ingreso por hidrocarburos en una medida que hace muy frágil cualquier previsión macro-económica. Las fluctuaciones del precio del crudo, repercuten de manera exagerada en el conjunto de la economía. Como muestra, las exportaciones petroleras contribuyeron en un promedio de $80 \%$ a las exportaciones totales entre 1985 y 1990 (2).

(1) Las cifras presentadas en este trabajo provienen de los Informes sobre el Desarrollo Mundial del Banco Mundial y de los Informes Económicos del Banco Central de Venezuela, ediciones de 1980 a 1992, a menos que se señale otra fuente.

(2) UNCTAD, Handbook of International Trade and Development Statistics, United Nations, New York, 1992. 
Se debe decir que en 1980, las manufacturas representaron ingresos por 300 millones de US\$, el $2 \%$ del total. En 1989, habían alcanzado el valor de 1.036 millones de US\$, representando el $8 \%$ del conjunto. Las exportaciones no tradicionales (se exceptúan el petróleo y los minerales como hierro y aluminio) alcanzaron cifras promedio de 3.000 millones de US\$ en los últimos años de la década de los ochenta, hasta 1992. Igualmente el valor agregado manufacturero pasó, en términos corrientes, de 2.140 millones de US\$ en 1970, a 12.373 millones en 1988. Haciendo una comparación internacional, Venezuela creció en este rubro mucho más que Argentina, y de manera similar a México (Argentina: 5.750 millones en 1970, 18.646 en 1988; México: 8.449 millones en 1970, 46.932 en 1988).

Con estos últimos datos se ejemplifica la importancia de las políticas económicas tradicionales para la expansión del aparato productivo. Sin embargo, hay que señalar que la mayor parte de las exportaciones no tradicionales se realizaron por el impulso de la devaluación del bolívar. El techo al que parecen haber llegado alrededor de los 3.000 millones de US\$ en los últimos años no podrá ser superado a menos de un incremento notable en la productividad y eficiencia de los factores de producción.

\section{c. Gasto público creciente.}

La práctica de los subsidios a la producción y al consumo, así como las transferencias a empresas públicas ineficientes, habían generado un nivel de gasto extremo que contribuyó al endeudamiento externo y al déficit fiscal. Los efectos inflacionarios han sido uno de los signos evidentes de esta situación, con todas las consecuencias negativas que se generan en estos casos para el comercio internacional, el ingreso interno real, la inversión y el bienestar de la población. Sobre este aspecto, se debe señalar que en 1988 el gasto público total representó el $71 \%$ del PIB, en tanto que en las estimaciones para 1991, después de tres años de ajustes, se calcula que el gasto público se acercó al 35\% del PIB.

\section{d. Monopolización de la economía.}

Otro efecto indeseado de las políticas económicas tradicionales fue el incremento de la monopolización de la economía. Un dato significativo de esta situación se expresa en 1987, cuando la gran industria, que representa el $8 \%$ del parque industrial, participó con el $77 \%$ del total de las ventas. La concentración del capital ha dismimuído notablemente la competencia interna, con lo cual, la estabilización de los precios o su descenso se hace casi imposible en condiciones de una economía excesivamente protegida frente al exterior.

\section{e. Fracaso del control de precios.}

La contrapartida de los subsidios y del proteccionismo era un control de la economía por parte el Estado, entre cuyos instrumentos más aplicados se encontraba el control de los precios.

En la práctica esa regulación era completamente ineficaz. Cada vez que algún sector de la economía tenía interés en aumentar los precios, se producía un desabastecimiento arti- ficial. Esto obligaba a claudicar al gobierno, el cual, después de amenazar con importaciones masivas del producto en cuestión, terminaba aceptando el incremento solicitado.

\section{EL PAQUETE ECONOMICO.}

Las medidas adoptadas en 1989 se resumen en los siguientes aspectos:

\section{a. Política de precios y subsidios al productor.}

Se liberaron los precios al consumidor en la mayor parte de los rubros para eliminar la casi totalidad de los subsidios al productor.

\section{b. Política comercial.}

Se estableció una escala de rebajas arancelarias anuales según las cuales el arancel máximo para 1990 fue de 50\%, en 1991 de 40\%, en 1992 debía ser de 30\% y en 1993 llegaría a 20\%. De hecho, en marzo de 1992 se decidió una rebaja para este año hasta un tope de $20 \%$, como consecuencia de acuerdos del Pacto Andino. Con esta medida se espera aumentar la competencia interna, moderar los precios y estimular un incremento de la productividad y la eficiencia del sector industrial y comercial. Igualmente se creó un fondo de estímulo a las exportaciones que ayudó mucho entre 1989 y 1990 a su desarrollo.

\section{c. Política fiscal.}

Se disminuyeron las tasas del impuesto sobre la renta y se planificó la creación de un impuesto al valor agregado, que aún no ha sido aprobado por el Parlamento (septiembre de 1992). Se ha hecho un intento de reducción del gasto público que, en términos reales, implica una disminución presupuestaria de 10\% en 1992 respecto a 1991. En caso de que el Congreso Nacional decida no crear el IVA, el déficit fiscal que soportaría Venezuela puede oscilar entre el 5\% y el $10 \%$ del PIB. La inflación que resultaría podría liquidar los efectos de recuperación económica y de las reservas internacionales que ha logrado tan penosamente el país.

\section{d. Política monetaria.}

La libre flotación del bolívar y la unificación de las tasas de cambio son las medidas más importantes de este período, junto a una intervención discreta del Banco Central para permitir microdevaluaciones de la moneda. Tal vez el mayor éxito de esta política ha sido el mantenimiento promedio de un nivel competitivo del bolívar (con eventuales períodos de sobrevaluación) y la eliminación de la fuente de corrupción del sistema de cambio preferencial que prevaleció entre 1983 y 1989.

\section{e. Política social.}

De un sistema de subsidios al productor, se pasó a un sistema de subsidios a la población más pobre. En vez de productos baratos de los que se beneficiaban todos los sectores, incluyendo a los más ricos, se estimuló el consumo de la población de bajos ingresos a través de diversos programas de distribución de bonos y alimentos, así como de atención a las madres embarazadas y a los niños menores de cinco años. 


\section{f. La privatización.}

Como en otros países de la región, la privatización de entes del Estado ha sido una de las prioridades del gobierno. Prácticamente ninguna empresa queda fuera de los planes de desestatización. Hasta ahora se han vendido, entre otros, bancos, líneas aéreas, centrales azucareros, cementeras, hoteles y astilleros.

\section{LA REACCION.}

En un país acostumbrado a la bonanza como Venezuela, estas medidas fueron muy mal recibidas por diferentes sectores.

En primer lugar, una porción importante de los empresarios que había florecido a la sombra del Estado, se mostró airadamente contraria a la política comercial y a la eliminación de los subsidios, aunque calló sobre la liberación de precios. La industria automotriz fue particularmente crítica en este asunto.

Las capas de políticos más tradicionales, que manejaban el gasto público como un mecanismo de distribución de prebendas a su clientela, y como cimiento de su propio poder, se vieron de un momento a otro alejados del gobierno y amenazados de extinción. Los sindicatos se opusieron igualmente a las medidas por lo que representaban de contracción del ingreso. Ambos, estrechamente involucrados con los partidos políticos, provocaron un fenómeno de oposición generalizada al gobierno casi desde su inicio, al extremo de que Acción Democrática, el partido del Presidente, luce tan opositora como los demás.

Por otro lado, fuerzas muy importantes de la sociedad como sectores fundamentales de los empresarios, gran parte de la tecnocracia pública y privada, intelectuales y grupos minoritarios de todos los partidos políticos apoyaron las políticas de reestructuración.

El 27 de febrero de 1989, pocas semanas después del cambio de gobierno, una ola de saqueos conmovió al país. En su momento se interpretó, con poco sustento, que se debía a las recién anunciadas medidas. Tres años después, el 4 de febrero de 1992, un intento de golpe de Estado produjo una de las crisis políticas más graves de los 34 años de democracia venezolana. En ese momento, otra vez, los dirigentes partidistas asociados a las viejas escuelas clamaron contra el paquete económico y explicaron la aventura como una reacción contra las políticas impuestas por el Fondo Monetario Internacional. A las voces de reacción esperadas, se sumaron las manifestaciones de amplios sectores de la población en contra no ya de las medidas económicas, sino de las instituciones de los partidos, el Parlamento, el Poder Judicial y el Gobierno mismo.

\section{LAS REFORMAS POLITICAS Y LA DESCENTRALIZACION: UN INTENTO POR SALVAR LA DEMOCRACIA.}

Las explicaciones que ciertos sectores dan del golpe fallido y de la inestabilidad que le sucedió son básicamente interesadas.
Venezuela se encuentra ante la encrucijada más importante de su historia democrática. Entre el 27 de febrero de 1989 y el 4 de febrero de 1992 corrieron casi tres años, y toneladas de descrédito para el sistema político imperante.

La primera fecha simboliza la disolución de las fronteras entre el vandalismo y la desesperación del pueblo. Cuando vastos sectores populares se entregan al pillaje y al saqueo, estamos en presencia de una peligrosa alianza entre la delincuencia y el hambre. Pero, sobre todo, este fenómeno expresa la incapacidad de las instituciones para dar respuesta a las demandas de esa parte de la sociedad, así como a las de otros grupos que por miedo o pudor no se lanzaron a las calles en esa ocasión.

El segundo acontecimiento es aún más grave que el anterior. Un puñado de militares atentaron contra la democracia, pensando tal vez que su gesto sería apoyado y aplaudido por la mayoría. Cometieron un error grave. Los acontecimientos posteriores demuestran que el apego al sistema democrático es muy fuerte entre los venezolanos. Sin embargo, nada podrá borrar el hecho de que la desilusión generalizada de la población sobre el funcionamiento del Estado, de la justicia y de los partidos, fueron factores que dieron alas a esta aventura.

Dicho ésto, parece excelente la oportunidad para disentir de aquellos que achacan a la política económica del gobierno la causa de todos los males de la nación. Hay quiénes han convertido al paquete económico en el gran villano de la película. Es una forma sencilla y eficaz de venderse como chicos buenos y recolectar votos para las próximas elecciones. Pero, es también una manera muy hábil de evadir responsabilidades sobre las profundas transformaciones que requiere el sistema político y la estructura económica.

No hay duda de que las medidas de ajuste en la economía causaron una disminución en el ingreso real. Este es el efecto que más se siente en el corto plazo y el que tiene más potencial desestabilizador. Ahora bien, un país con problemas económicos como Venezuela, pero con instituciones creíbles y justas, en las que la población confíe, reaccionaría ante esas dificultades con voluntad de trabajo y de superación. Un país así le daría al futuro un crédito razonable, seguiría a sus líderes con entusiasmo, como ha sucedido en tantas otras naciones en momentos de turbulencia.

Por el contrario, una nación con instituciones débiles y desacreditadas, reaccionará ante la penuria económica con desesperanza y violencia. Y más si sus líderes no muestran la decisión y voluntad necesarias para apoyar los cambios que aumentarían la confianza de la sociedad en el sistema.

Una de las causas más profundas de deslegitimación del régimen y de disminución de la gobernabilidad es la indefensión que buena parte de la población siente frente a un Estado que no le rinde cuentas y a un sistema electoral en el que salvo para elegir al Presidente de la República, se votaba por listas de partidos en las que ni siquiera se especificaban los nombres de los candidatos a concejales, diputados y senadores. 
En una situación de esta naturaleza, ya visible hace varios años y sólo agudizada por los acontecimientos de febrero, es muy grande la tentación de retrotraer el sistema político hacia formas más represivas y centralizadas de poder.

Frente a este peligro el mismo gobierno de Venezuela creó la Comisión Presidencial para la Reforma del Estado (Copre) en 1985, integrada por representantes de los diversos partidos políticos, gremios, asociaciones empresariales y sindicales, universidades y agrupaciones ciudadanas con el objeto de revisar y proponer la reestructuración de las relaciones existentes entre el Estado y la sociedad venezolana.

La conclusión más importante a la que llegó la Copre se puede sintetizar en la idea de que las dificultades de legitimación del sistema político obligan a la profundización de la democracia.

En este sentido, se propuso que los gobernadores de Estados, que hasta 1989 eran designados por el Presidente de la República, fueran electos por la población. Asimismo, se insistió en la creación de la figura del alcalde, vieja tradición española desaparecida en Venezuela, con el fin de separar el poder legislativo y el poder ejecutivo en los concejos municipales. Igualmente se diseñó un sistema electoral nominal para los concejales, que incrementara su responsabilidad personal frente a los electores. Estas proposiciones, bases de la descentralización, se transformaron en leyes, con una notable resistencia de algunos estamentos políticos, pero con un apoyo masivo de numerosos sectores de la población que presionaron hasta lograr estos objetivos.

Las elecciones de gobernadores y alcaldes, realizadas en diciembre de 1989, transformaron los mecanismos de representación radicalmente. Los mandatarios regionales y locales están sometidos a un control electoral y a presiones cotidianas de esas mismas comunidades que difícilmente encuentran interlocutores en la administración pública central.

Ahora bien, hay quiénes sostienen que el país será ingobernable, que aumentará la ineficiencia y que se comete un error con esta apertura democrática. Otros son escépticos, desconfían de la clase política y le atribuyen la capacidad de burlar las reformas. Finalmente, muchos se preguntan qué poder detentarán realmente estas nuevas autoridades, y cuánto de la vida cotidiana de las personas será afectada por este cambio.

Lo primero que habría que decir sobre esta controversia, es que el Estado venezolano se ha dado cuenta desde hace décadas de la necesidad de descongestionar los lugares donde se toman decisiones. Para cualquier gerente no es un secreto que la eficiencia depende mucho de que cada integrante de una organización, asuma responsabilidades que permitan a la cúpula de la dirección concentrarse en los planes estratégicos y globales, mientras que en el resto de los niveles se resuelven problemas más concretos.

Esta sencilla norma ha sido propuesta por todas las comisiones de reforma administrativa que han existido desde principio de los años sesenta en Venezuela. El resultado de estos planteamientos se expresa en un amplio proceso de desconcentración de muchos entes públicos. Casi todos los ministerios tienen delegaciones en diferentes regiones del país, con la intención de que los problemas locales sean resueltos por funcionarios de la zona. Sin embargo, la evaluación de esta experiencia arroja un balance desastroso. La autoridad realmente delegada es mínima y los problemas siguen resolviéndose (¿o habría que decir no resolviéndose?) en Caracas. La tradición presidencialista influye mucho en la reticencia que se tiene, a nivel central, de distribuir poder de decisión hacia los subordinados. A su vez, el agente de los organismos públicos en las localidades, dirige su lealtad hacia el ministro, director o compañero de partido que lo nombra, y normalmente no siente compromiso con una población que tiene muy pocos medios para hacer valer sus derechos.

\section{DESCENTRALIZACION Y PARTICIPACION.}

Esta situación es la que se ha pretendido modificar con la elección directa de los gobernadores y alcaldes, y la transferencia progresiva de responsabilidades hacia estos niveles de gobierno. Así, las comunidades tendrán un instrumento, hasta hace poco inexistente, para hacer rendir cuentas en las elecciones a aquellos funcionarios que no hayan cumplido sus compromisos. Nadie estará más interesado que la misma población atendida por los gobiernos regionales y locales, en aumentar la calidad de los servicios prestados por el Estado y disminuir sus costos unitarios simultáneamente. En este sentido, se puede esperar que muchas de las reivindicaciones que serán objeto de negociación entre las organizaciones sociales de las comunidades y los gobernantes, se dirigirán al aumento de la eficiencia de la administración pública de los estados y municipios.

Ahora bien, ¿cuál es la relación entre una mayor participación de las comunidades en las decisiones que corresponden al Estado y la descentralización? y ¿en qué influye la mayor participación en el mejoramiento de los servicios públicos?.

La respuesta es que cuando los gobernadores y alcaldes electos detenten mayores poderes, serán más responsables ante sus electores, y los ciudadanos podrán exigir directamente una gestión más democrática y más eficiente de la vida pública. En este momento, las múltiples tareas que le toca realizar al gobierno y la excesiva centralización que lo caracteriza no le permiten atender con la suficiente prontitud a todas ellas. Muchos asuntos locales son descuidados porque deben ser decididos en las más altas esferas de los respectivos ministerios o incluso, a veces, en la misma presidencia de la República. Con este esquema, ni las comunidades tienen acceso al proceso de toma de decisiones (porque se realizan muy lejos de ellas), ni se resuelven muchos problemas que podrían ser atendidos si los gobiernos estatales y municipales tuvieran las competencias necesarias para hacerlo. El principio que subyace a estas ideas es muy simple: más funciones de administración, en manos de entes más cercanos a la población, podrían ser mejor atendidas; mientras que menos funciones administra- 
tivas en el gobierno central le permitiría ocuparse de las decisiones de carácter estratégico. Este es el objetivo de la descentralización.

\section{LA ESTRATEGIA DE LA DESCENTRALIZACION O POR QUÉ SE COLOCO LA CARRETA DELANTE DEL CABALLO.}

En el complejo proceso que ha inducido el desarrollo de la descentralización en Venezuela, muchas veces se ha planteado la interrogante sobre por qué se eligieron primero a los gobernadores y alcaldes, y solamente después de ese hecho político se ha prestado atención a la transferencia de competencias administrativas y financieras hacia esos niveles de gobierno. Para algunos, esto mostraría improvisación de parte de quiénes han estado involucrados en la toma de decisiones sobre este tema y, en todo caso, irracionalidad técnica.

Ciertamente, las condiciones en las que se ha desarrollado la administración pública venezolana en las últimas décadas, han dejado una herencia muy desequilibrada: las capacidades de gestión localizadas en los gobiernos regionales y locales, así como sus competencias, son actualmente muy escasas, mientras que el gobierno central ha concentrado la mayor parte de las funciones del Estado y de su estructura organizativa. Las causas de este fenómeno son numerosas, pero entre las más notorias podemos encontrar al menos tres.

La primera es de carácter histórico. El siglo XIX se caracterizó por una permanente tensión entre los caudillos regionales y la formación del Estado-nación. Los proyectos políticos que proponían la constitución de una sociedad moderna, tenían en común un énfasis en el centralismo, única vía posible para imponer una organización general de los intereses nacionales sobre los cálculos parciales de los líderes locales.

La centralización como vía de consolidación del Estadonación fue considerada como positiva por la mayor parte de las fuerzas políticas y sociales que apoyaron la modernización del país, y se realizó a costa de la autonomía de las regiones.

El segundo factor que incidió en el proceso de centralización, es la presencia dominante de los partidos políticos en el aparato de Estado, desde los años sesenta en adelante. Este vínculo ha sido de la mayor importancia para la organización y el crecimiento de las instituciones partidistas. Desde el Estado, los partidos que han gobernado, lograron reclutar militantes y acumular adhesiones mediante la repartición de prebendas y cargos burocráticos. Como ejemplo del crecimiento del personal al servicio del sector público, se puede señalar que en 1973 los funcionarios alcanzaban la cifra aproximada de 300.000, en 1978 de 700.000, en 1983 llegaron a 1.000 .000 y en 1988 a 1.200 .000 , cifra que ha descendido ligeramente desde entonces. A su vez, la ideología estatista que ostentan los partidos venezolanos desde la década de los cuarenta en adelante, es un elemento que con- tribuyó a sustentar las tendencias centralizadoras.

En la medida en que la centralización de la administración pública acumulaba las decisiones y la capacidad financiera en el ejecutivo nacional y su gabinete, la necesidad de controlar este nivel del gobierno provocó en los partidos un interés especial en fortalecer sus actividades en Caracas. A más relevancia del centro en la toma de decisiones, más decisiones se le encomendaban, más recursos humanos y financieros eran atraídos hacia el gobierno nacional y más consenso se levantaba entre los partidos en favor de mantener este esquema cíclico. El debilitamiento institucional y financiero de la provincia fue cada vez mayor. Del mismo modo, la tendencia a perpetuar un sistema político regional dependiente del centro y de los partidos se acentuó cada vez más: designación presidencial de los gobernadores, elección de segundo grado del presidente de los ayuntamientos en condiciones en las que el poder ejecutivo municipal estaba supeditado y fundido al legislativo, elecciones de concejales y diputados estatales por listas cerradas y bloqueadas que favorecían a los candidatos designados por las formaciones partidistas.

Finalmente, la debilidad de la sociedad venezolana durante buena parte del siglo XIX y XX, fue contrabalanceada por la presencia creciente del Estado y de pocos grupos de presión relacionados directa o indirectamente con los caudillos (en el XIX y comienzos del XX) o con los partidos (en las últimas décadas). La escasa constitución política de las sociedades regionales, salvo algunas excepciones, las mantuvo primero sometidas al caudillismo, y después al partidismo. En la mayor parte de los Estados no se logró consolidar una estructura de poder apoyada en una sociedad civil local madura. Esta carencia impidió la puesta en pie de instituciones administrativas propias que trascendieran las maneras personalistas de gestión de los cabecillas provincianos. Una de las consecuencias de esta situación, fue la asunción, por parte del centro, de funciones tradicionalmente propias de los estados o, incluso, de los municipios, como la prestación de los servicios públicos y la planificación urbana.

Dicho lo anterior, podemos retomar la discusión planteada al comienzo de este punto y tratar de responder por qué se dieron primero los pasos políticos de elección de autoridades, antes que transferir funciones y financiamiento a las regiones y localidades. Plantear este tema es entrar en lo más esencial de las razones que provocaron el desarrollo de la descentralización en el país.

El cambio más importante que ha sufrido Venezuela, en los últimos treinta años, es el de la formación de nuevas fuerzas sociales y la transformación de las existentes anteriormente. Esta evolución, está muy relacionada con una de las premisas más defendidas por los partidos políticos desde la década de los cuarenta: la escolarización masiva. Como una de sus consecuencias tenemos un incremento de la asistencia de la población al sistema formal de educación, que ha hecho pasar la tasa bruta de escolaridad en primaria de un $51.1 \%$ en 1950 a $93.3 \%$ en 1981 ; en media de $3 \%$ en el 50 a $45.7 \%$ en el 81 y en superior de $1.3 \%$ a $19.8 \%$ en los 
mismos años. Este acontecimiento, a pesar de una baja aparente de la escolarización en los años recientes, ha producido un desarrollo significativo de lo que podríamos denominar como la cultura de la modernidad.

Esta evolución, junto con un innegable esfuerzo económico, han abonado el terreno y contribuído a la aparición y consolidación de nuevos fenómenos socio-políticos. Nos encontramos con que en las ciudades se han agrupado sectores de la clase media a través de asociaciones de vecinos, ambientales, culturales y deportivas; en la provincia los empresarios pequeños, medianos y grandes se han fortalecido progresivamente; el sector tecnocrático del Estado ha adquirido una presencia y capacidad de decisión creciente, en competencia con la burocracia de origen clientelar; los gremios profesionales y obreros se han visto obligados a profundizar sus actividades; los grupos empresariales más poderosos se han dividido sobre lo que debe ser la estrategia de desarrollo del país entre los que esperan que el Estado continúe protegiéndolos e interviniendo, y los que están conscientes de la necesidad de enfrentar el mercado sin la tutela de los gobiernos de turno.

Si algo tienen en común estas nuevas fuerzas, y las nuevas orientaciones de fuerzas más tradicionales, es su interés en formular políticas sectoriales sobre temas que les interesan; su autonomía del Estado y, la mayor parte de ellas, de los partidos; su activismo político y la capacidad de generación de opinión pública. En general, son adversas a la burocracia y coinciden en su apoyo a la descentralización, entre otras razones, porque es el mejor mecanismo para romper el monopolio de los partidos sobre las decisiones que afectan a las comunidades de intereses regionales y locales.

Ahora bien, los adversarios del proceso descentralizador, principalmente parte de la burocracia partidista y algunos sectores de las direcciones de los partidos políticos, junto con fracciones de gremios empresariales y obreros, son fuerzas de la mayor importancia aún. Lo eran más todavía en los años 86-89, período en el cual se produjo el debate nacional sobre la descentralización, que encontró como oponentes a sectores del gobierno anterior (1984-1989) y a influyentes personalidades de la élite política del país.

En Venezuela, la historia enseña que, en general, contra el gobierno no se puede. Sin embargo, durante el lapso en cuestión, una coalición sin precedentes de fuerzas sociales, logró desatar una de las campañas más dinámicas y efectivas de las que se recuerde, en favor de la descentralización, enfocando las reivindicaciones alrededor de temas muy concretos, pero con efectos multiplicadores grandes, como las elecciones nominales de las autoridades locales y regionales. Fue ese frente inusual el que logró doblegar los intereses contrarios a la descentralización y hacer que se aprobaran instrumentos fundamentales para el proceso como la reforma de la ley Orgánica de Régimen MunicipalL.O.R.M. (que creó la figura del Alcalde y separó los poderes legislativo y ejecutivo a nivel local, desarrollada posteriormente con un reglamento que consagra avances importantes en las posibilidades de participación de las comunidades en los asuntos locales), la ley de Elección y Remoción de los Gobernadores de Estado (que deroga el privilegio presidencial para nombrar gobernadores), la reforma de la ley Orgánica del Sufragio (que hace más nominales las elecciones de los cuerpos legislativos, aumentando la exposición de los electos a sus comunidades de electores) y la ley de Descentralización y Transferencia de Competencias del Poder Público Nacional a los EstadosL.O.D. (que define competencias de carácter exclusivo y enumera competencias concurrentes de los Estados).

Si se hubiera insistido, en aquella época, en la transferencia de competencias administrativas y financieras antes de la elección de alcaldes y gobernadores, a entidades gubernamentales dominadas por las mismas fuerzas que se negaban a la descentralización, muy probablemente no se hubiera logrado nunca el despegue del proceso que hoy existe en Venezuela. No se habrían aglutinado las fuerzas que lo hicieron porque los objetivos habrían sido más difusos, y la resistencia a la puesta en marcha de una real descentralización por parte de muchos administradores locales y regionales de entonces, habría arrojado resultados negativos del proceso que desestimularían seguir adelante con la elección libre y popular de autoridades. Esta es la razón por la cual la estrategia de la descentralización en Venezuela pasó por una primera fase política y sólo después pudo comenzar la fase administrativa.

\section{LA REESTRUCTURACION DE LA ADMINISTRACION CENTRAL.}

La descentralización obliga a repensar un espacio de vital importancia para la administración del Estado: las funciones y las dimensiones de la administración pública central.

Cuando el gobierno de Carlos Andrés Pérez emprendió la iniciativa de reestructurar la administración central en 1989, los dos ejes privilegiados fueron la privatización de las empresas públicas y la reestructuración de los ministerios y entes autónomos. La idea que prevalecía entonces era que se debía redimensionar el gobierno, deslastrándolo de actividades que generaban déficit al sector público o que no se justificaban en manos del Estado. Los dos elementos del programa inicial han corrido con diversa suerte. La privatización ha avanzado con paso más firme que la modificación estructural de los ministerios e institutos dependientes de la administración central.

En todo caso, lo que es cierto para ambos esfuerzos es que, hasta hace poco, no se consideraba necesario establecer una relación con el proceso de descentralización. Esta desconexión ha provocado algunas fricciones innecesarias entre la Nación y los Estados. Dos casos ilustran la situación que se planteó.

El primero se refiere a los puertos. El gobierno decidió la privatización de estos servicios como uno de los primeros pasos del programa de reestructuración-privatización a ejecutar en el período 90-91. Se planteó inicialmente la entrega de las actividades portuarias al sector privado y, simultánea- 
mente, la liquidación del Instituto Nacional que se encargaba del sector (INP), reduciéndolo a una dependencia dentro del Ministerio de Transporte y Comunicaciones. Esta estrategia no consideraba que la ley de descentralización entregaba a los Estados, como competencia exclusiva, la administración de los puertos públicos de uso comercial, desde el momento mismo en que éstos los asumieran por ley estatal.

Como consecuencia de este plan, algunas gobernaciones, particularmente las más interesadas en el tema, enfrentaron la decisión del gobierno y adelantaron la aprobación de leyes que ponían los puertos bajo el control de los Estados. En un primer momento el INP reaccionó tratando de forzar el proceso de privatización. Felizmente, después de la intervención de la Copre, se entró en una fase de negociación que culminó en diversos convenios entre la Nación y los Estados. El resultado de estos acuerdos es que se realizó la liquidación del INP, se entregaron los puertos a los Estados y se privatizaron la mayor parte de los servicios portuarios, bajo la autoridad de las gobernaciones.

El segundo caso se refiere a las vías de comunicación terrestres. Uno de los servicios que se pensaba privatizar más rápido era justamente el de la administración de las autopistas, otra competencia exclusiva de los Estados. Durante los años 90-91, el Ministerio de Transporte y Comunicaciones (MTC) diseñó una estrategia de entrega de estos servicios a empresas privadas. Nuevamente, algunos Estados aprobaron leyes o manifestaron su voluntad de asumir las vías terrestres. El Ministerio reaccionó rápidamente y durante 1992, por iniciativa propia, apoyado nuevamente por la Copre, se realizaron acuerdos con la mayoría de los Estados para producir una transferencia concertada de estas infraestructuras y garantizar simultáneamente la pervivencia del principio de gestión privada de las mismas. De hecho, hay que reconocer que ésta fue la primera vez que el gobierno nacional tuvo una iniciativa de descentralización, y sus resultados han sido muy importantes, tanto desde el punto de vista del ordenamiento de la transferencia de una competencia tan estratégica para el país, como desde el ángulo de la señal de voluntad política descentralizadora que se dio a los Estados.

El impacto de la descentralización sobre el personal al servicio del Estado es innegable. Del gobierno nacional dependen algo más de 1.100 .000 empleados, como ya se señaló. De éstos, 450.000 son funcionarios de la administración central (ministerios) (3), y el resto se reparten entre los institutos autónomos como el de la vivienda, el agua, el deporte, protección a los menores y los ancianos (también sujetos a descentralización), y las empresas públicas (sujetas éstas a privatización). Consideremos que tan sólo en los sectores de educación y salud, serán transferidos más de 300.000 cargos de la Nación a los Estados en los próximos años. Tomando en cuenta todos los sectores de la administración central y de los institutos autónomos descentralizables, se puede afirmar que aproximadamente el $70 \%$ de los funcionarios que trabajan en ellos pasarán a formar parte de las administraciones estatales en un lapso de dos a seis años (4).

En conjunto, la fisonomía del Estado venezolano en el umbral del siglo XXI será muy diferente de la que hemos conocido en las últimas décadas. El gobierno central se reducirá en tamaño considerablemente. Las administraciones ministeriales retendrán una cantidad de funcionarios muy inferior a la actual, en vista de que buena parte de ellos están actualmente ocupados de funciones operativas que serán entregadas a los Estados (p.e. maestros, médicos). Igual sucederá con los institutos autónomos dependientes de los ministerios. Este tipo de organismos tenderán a fusionarse, e incluso algunos de ellos desaparecerán. Un proyecto de ley de la administración central que está bajo estudio en el Congreso, adelanta la idea de una reducción de los dieciséis ministerios actuales a nueve. A su vez, algunos institutos autónomos están siendo liquidados. Independientemente del número final que alcancen los ministerios y de los institutos autónomos que sobrevivan, la tendencia que parece perfilarse, estrechamente relacionada con la descentralización, es la de una disminución del volumen de funcionarios y operaciones del gobierno central. La privatización que se ha venido realizando de numerosas empresas públicas acentúa aún más este escenario.

Por otro lado, las administraciones estatales y municipales crecerán en los próximos años en una proporción probablemente superior a la disminución que experimentará el centro. Como ya se mencionó, estos niveles gubernamentales tenderán a ampliar la cobertura y calidad de servicios que actualmente son deficitarios, tanto en financiamiento como en personal. De ser así, se producirá el ingreso de un cierto volumen de nuevos funcionarios en estos niveles, a pesar de una corriente claramente definida en las gobernaciones y alcaldías de entregar en concesión al sector privado la administración de numerosos servicios.

El factor aún poco definido que permitiría apreciar con mayor precisión el fenómeno que analizamos es el comportamiento de los servicios transferidos. En manos del gobierno nacional existen organismos que cargan con un número de trabajadores injustificado. Ese era el caso del Instituto Nacional de Puertos. Su nómina ascendía a unos siete mil empleados. Después de su liquidación, los Estados han entregado a diversas compañías privadas las operaciones portuarias y han creado organismos de administración que emplean a unas pocas decenas de personas. Si ésta fuera la tendencia general, se podría pensar incluso en una disminución global del número de empleados públicos. A su vez, los Estados y municipios más grandes tienen un exceso de funcionarios administrativos y obreros (5), que pueden disminuir con el tiempo. Sin embargo, en los servi-

(3) Oficina Central de Presupuesto del Gobierno de Venezuela. Ley de Presupuesto de 1992

(4) La transferencia de los servicios educativos y de salud serán prioritarias en los próximos tres años. Se ha estimado que la mayor parte de personal dependiente de los Ministerios de Educación (250.000 aprox.) y de Sanidad (100.000 aprox.), pasarán a formar parte de la función pública estatal. Otros ministerios y consejos que serán afectados por las transferencias son la familia, ambiente, desarrollo urbano, transporte y comunicaciones, agricultura, energía y fomento, cultura y ciencia tecnológica.

(5) El gobernador de Zulia, el mayor Estado del pais, afirma que sólo son necesarios 7.800 de los 20.800 empleados y obreros con los que cuenta actualmente la gobernación. Cf. Entrevista. La revista de Caracas. Caracas, 23-8-92. 
cios más consumidores de empleo, como salud y educación, la norma probablemente será la de un aumento discreto pero sostenido de funcionarios. De este modo, se puede esperar en las regiones y municipios una retracción progresiva del empleo administrativo y un aumento del empleo dedicado a operaciones de los servicios sociales básicos.

\section{CRISIS POLITICA Y PERSPECTIVAS DE UN NUEVO PACTO SOCIAL: CONSTITUCION Y DESCENTRALIZACION.}

Nunca hasta ahora, un país de América Latina ha logrado reformar un régimen agotado, respetando las reglas de juego democráticas. Estamos acostumbrados a presenciar que las democracias, una vez que entran en graves crisis como la venezolana, son substituídas por dictaduras. A su vez, los gobiernos autoritarios sucumben eventualmente frente al empuje y las aspiraciones de libertad de la mayoría de la sociedad. La mayor parte de nuestra historia está marcada por este movimiento pendular.

En Venezuela, se está produciendo en los últimos años una transformación profunda tanto del sistema político como de la estructura económica, de consecuencias tan impactantes, que ya debía haber desembocado en una dictadura, si hacemos caso a los antecedentes.

Sin embargo, la magnitud del viraje que estamos presenciando, es una respuesta contundente, dentro de la democracia, a la decadencia del modelo que heredamos del comienzo del actual período democrático en 1958. Este es el valor inmenso de la experiencia venezolana: frente a la ineficacia e incluso desmoronamiento de las instituciones públicas, se ha respondido con la profundización de la democracia, que es el sentido básico de la descentralización.

Nos encontramos así ante una situación de cuyo desenlace puede depender el destino del país. $\mathrm{O}$ avanzamos en los cambios estructurales del Estado y de su relación con la sociedad que tienden a modernizar su economía y democratizar sus estructuras políticas, o renacerán los sectores que esperan un retroceso a antiguas prácticas populistas. De triunfar éstos últimos, existe el riesgo de que se produzca un salto al vacío de nuevas experiencias autoritarias disfrazadas de nacionalismo.

El peligro más grave que amenaza a la democracia en nuestro país es la desconfianza creciente de buena parte de la población en las instituciones públicas. Desde los partidos políticos hasta el sistema judicial, pasando por el parlamento y el mismo ejecutivo, son blanco de críticas y descreimiento.

Esta situación es abonada por el hecho de que la democracia venezolana se ha basado en un sistema de representación partidista. En otras palabras, las cúpulas de los partidos decidían quiénes ocupaban cargos públicos, hasta el extremo que cuando se llamaba a votar, lo hacíamos sellando unas tarjetas de colores sin identificación alguna de los nombres de aquellos que estabamos eligiendo. De este modo, los electos para administrar el Estado, mostraban su lealtad más a sus jefes en los partidos que a sus electores. La consecuencia de este sistema ha sido un alejamiento progresivo entre la sociedad y el mundo político.

La crisis que se desató desde el 4 de febrero de 1992, a partir del frustrado golpe de estado, trasciende así las fronteras del desacuerdo con la gestión de gobierno. Se trata de una crisis política y social que se expresa como una crisis de legitimidad de las instituciones públicas y, particularmente, de la élite política.

En respuesta a esta desafección de la población, los dirigentes de los partidos, representados especialmente en el Congreso nacional, emprendieron una revisión de la Constitución, para tratar de responder a las demandas de reformas que anteriormente desestimaban.

El Congreso discutió entre 1990 y principio de 1992 una enmienda constitucional muy limitada a determinados aspectos. A raíz de los acontecimientos de febrero, esta enmienda se ensanchó hasta alcanzar las dimensiones de una reforma general de la Carta Magna, incluyendo numerosos temas sobre descentralización, no considerados en la enmienda.

Resumiendo los temas tratados en esta reforma se podrían desglosar en: actualización de la Constitución relativa a la elección directa de los gobernadores; ordenamiento de las competencias exclusivas y de los servicios concurrentes de cada nivel gubernamental; competencias tributarias y financieras de los Estados; descentralización del poder judicial y del defensor del pueblo, el consejo de administración federal (como órgano de administración de las relaciones entre el gobierno central y los Estados) y sistemas electorales locales.

Proposiciones de este género son válidas en cualquiera de los escenarios democráticos que se pueden prever como salidas de la crisis.

Si el referéndum que debe decidir sobre la proposición de reforma de la Constitución se lleva a cabo y se aprueban los cambios en el sentido de la propuesta llevada al congreso, la descentralización tendrá un apoyo constitucional mayor del que ahora posee.

Si el referéndum fracasa, bien sea por la abstención de los electores o por su rechazo, se pueden presentar tres alternativas principalmente. La primera es el llamado a elecciones anticipadas que podría realizar el Congreso mismo. En este caso, el nuevo Parlamento debe legislar para avanzar en la descentralización. La segunda posibilidad es la convocatoria a una Asamblea Constituyente que debería tomar el asunto de la descentralización como un eje fundamental de su trabajo. De esta manera, un nuevo pacto político puede traducir un verdadero nuevo pacto entre las fuerzas modernas de la sociedad que rechazan las políticas económicas populistas y el Estado centralizado. La tercera opción sería la continuación del mandato actual de los poderes públicos hasta diciembre de 1993, sin convocatoria a la Asamblea Constituyente. Esta posibilidad 
abriría un campo de inestabilidad adicional al gobierno. En caso de empezar la campaña electoral nacional en estas condiciones, la descentralización se convertirá sin duda en uno de los temas más importantes, alrededor del cual las diversas fuerzas políticas y sociales activas, intentarán llegar a acuerdos que amplien sus posibilidades respectivas de victoria.

La gobernabilidad del sistema tiene mucho que ganar con el proceso de descentralización. De hecho, después del intento de golpe, pocos dudan de la contribución que realizaron los gobernadores a la estabilidad de las instituciones, poniendo en juego su legitimidad y prestigio a favor de la democracia.

Si es cierto que los mecanismos de mediación como los partidos se han debilitado y que las instituciones del Estado no son confiables, una buena manera de restablecer la legitimidad de la democracia y de aumentar la base de gobernabilidad es apoyar la ampliación de la participación de la sociedad en los asuntos que le conciernen, así como de aumentar la eficiencia y eficacia gubernamental.

El esfuerzo y la apuesta bien valen la pena. La descentralización y la modernización del Estado encierran la promesa de una relación entre lo público y lo privado más sana y estable. La condición para el desarrollo de América Latina, desde la perspectiva de Venezuela, está muy atada a la recuperación de la fe de los pueblos en lá democracia. Y esta nueva ilusión debe provenir de la liquidación definitiva del populismo y de las instituciones caudillescas del pasado, para dar paso a nuevas formas de representación política, basadas en el ensanchamiento de los poderes de la sociedad frente al Estado. Ese es el reto más importante que tiene el continente enfrente. Si logra superar esta encrucijada, las reformas económicas serán más viables y aceptadas. En caso contrario, probablemente no veamos el desarrollo de esta nueva era de democracia que sacude a América Latina.

\title{
RESUMEN
}

El autor muestra, desde la experiencia venezolana, que la decadencia de las instituciones políticas populistas tiene la mayor responsabilidad en la crisis que atraviesa América Latina. La reforma del Estado, en sus aspectos económicos, políticos y administrativos, debe entenderse como una oportunidad para restablecer la gobernabilidad y preservar la democracia en el continente.

\begin{abstract}
By looking at the Venezuelan experience, the author shows that the decline of the populist political institutions is the main cause of the crisis that Latin America is going through. The reform of the State in its economic, political and administrative aspects must be understood as an opportunity to restore the governance of the system and to preserve the democracy in the continent.
\end{abstract}

